\title{
Spontaneous Cities: Lessons to Improve Planning for Housing
}

\author{
Nikos Angelos Salingaros
}

check for

updates

Citation: Salingaros, N.A. Spontaneous Cities: Lessons to Improve Planning for Housing. Land 2021, 10, 535. https://doi.org/ 10.3390/land 10050535

Academic Editor: Dagmar Haase

Received: 1 May 2021

Accepted: 18 May 2021

Published: 19 May 2021

Publisher's Note: MDPI stays neutral with regard to jurisdictional claims in published maps and institutional affiliations.

Copyright: (C) 2021 by the author. Licensee MDPI, Basel, Switzerland This article is an open access article distributed under the terms and conditions of the Creative Commons Attribution (CC BY) license (https:// creativecommons.org/licenses/by/ $4.0 /)$.
Departments of Mathematics and Architecture, The University of Texas at San Antonio, One UTSA Circle, San Antonio, TX 78249, USA; yxk833@my.utsa.edu

Abstract: The world can learn two key lessons from spontaneous settlements: (i) design so as to adapt to human biology; and (ii) design to save energy. Timeless processes of urban growth and sustainability have forced societies to conserve energy. Yet, nowadays, a profession focused on design ideology and short-term profit discredits many economical and effective long-term design methods. Decision-makers, politicians, and urbanists talk of energy conservation while continuing to use failed notions of industrial urbanity in place of documented solutions that work. Most damaging is the myopic academic elite's fixation on an unsustainable industrial-modernist visual vocabulary of minimalist forms. By promoting typologies based on images dating from the 1920s, instead of using scientific analysis, the industry serves extractive global imperialism rather than satisfying the world's population needs. We should instead learn from how self-builders adapt form, geometry, materials, surfaces, and ornament to maximize the user's emotional experience in an otherwise extremely challenging environment.

Keywords: human-centered design; informal cities; spontaneous settlements; organic growth; sustainability; urbanism; planning

\section{Introduction}

The world's growing population crisis pushes over 1 billion city dwellers (out of a total of 4 billion) to live in informal conditions [1]. Informal urbanism has serious problems (Dharavi in Mumbai; the favelas in Rio de Janeiro). Yet, internal conditions force residents towards some limited sort of sustainability. Energy use is minimal for the simple reason that none is available, while centrally generated energy sources are often pirated to support life very efficiently. Informal settlements are forced to use less energy, but with improved conditions, their residents will consume more to mimic the wealthier classes.

Urbanists concerned with housing know the importance of defining acceptable conditions of thermal comfort and sanitary installations in a proper house. These points are of paramount importance for zero-energy buildings and related legislation, which concern housing for all income levels, not only the poor. We can indeed learn how to improve planning for housing from spontaneous cities. At present, the lack of adequate policies from political parties prevents a solution to the problems of poverty and urbanism. I argue, in this paper, that the accepted solutions-more comfort obtained through energy wastage, which drives colonialism-are not sustainable.

Owner-built structures are unfettered by formal design, as the spontaneous building process mimics biological growth [2,3]. Incremental piecemeal construction spread over time is the opposite from the top-down schemes beloved by governments. This step-by-step adaptation implements biophilia (the love of natural forms) in the organic geometry of the city's structure, which actually leads to a more robust system that is adaptable and not monolithic [4]. Biophilia's other component-trees and green spaces-is problematic because all space is occupied, and trees tend to be used up for building materials and fuel.

Humans did not evolve to be able to design buildings and cities, nor to conserve and use the land in a sustainable manner. The "art of city building" has a limited evolutionary foundation, and it is, for this reason, subject to catastrophic errors. We can only learn from 
what has worked in the past, taking into account all of its consequences on the landscape. Here, practitioners come up to the early 20th century discontinuity, when traditional models for urbanism were discarded in favor of untested utopian visions of the future. The result was the growth of the architecture-industrial complex, which has competed head-on, ever since, with spontaneous building.

This paper employs the terms "industrial urbanity" and "industrial-modernist visual vocabulary of minimalist forms" to criticize current planning practice. It is useful to define these here. An industrial approach took over design and planning (one century ago), believing in the superiority of solutions based on economies of scale and standardization. However, attached to this implementation, yet hardly ever questioned, is a vocabulary of severely abstract geometries and forms, and a preference for industrially produced materials. As industrial production was firmly behind applying this paradigm to planning for housing, the geometry of spontaneous cities automatically became an ideological adversary that threatened "progress".

Given its manifold problems, the spontaneous city is not a good model of good urbanism. Nevertheless, several researchers wish to extract a few positive qualities from a bad model and apply them to the formal city. Those qualities are entirely missing from the common industrial model of top-down housing. Details of how design is motivated and implemented by self-builders, which get lost in the obvious deficiencies of the result, can be advantageously used within a better framework. Those design details better respond to human needs. This is especially important in mediating the conflict between high-density living and human-scale structures-a serious problem that has not yet been resolved.

This paper is addressed to the people whom I would encourage to change their practices and processes: architects, developers, financiers, politicians, and speculators. Some construction and planning done nowadays and in the past is actually quite good and should be emulated, whereas other work is inadequate (or even terrible) and should not be repeated. While understanding the contradictions and constraints under which every one of these actors works, I hope that the present discussion offers useful ways to improve the final product.

Shlomo Angel writes, at length, about the five elements of housing policy: adjudicating property rights, overseeing the housing finance sector, providing residential infrastructure, administering subsidies and taxes, and regulating land development and construction [5]. Governments are good at successfully performing these functions, but they are not very effective in building social housing, judging from the poor results from the perspective of the residents. Several countries have apparently abandoned social housing altogether, leaving that up to the private sector and, yet, the temptation to implement social engineering remains strong.

Some planning dos and don'ts are listed here, with arguments developed in the body of this paper. To begin with, assume that poor people will build their own houses; therefore, give them the freedom to do so and help them with some infrastructure that will be impossible to insert afterwards. Then, myriad potential problems arise, such as protecting the emerging larger public spaces from being encroached, protecting existing trees from being cut down, distributing any available funds among competing needs, such as road surfaces and the supply of electricity and water, etc. Perhaps the overriding question is: What are the self-builders' needs and priorities, versus what a patronizing elite thinks they are. In addition, we need to be receptive to solutions developed on the ground, especially if those do not fit with the formal planned city [6-8].

Among points that should be discouraged are top-down conceptions of a visually "neat" urban layout (Figure 1). Even urbanists with a progressive approach made this mistake, consequently generating an inhuman, monotonous city. Repetition unvaried by individualization becomes deadening. This suggests not starting from a rectangular grid of streets as if planning a formal city, but letting the terrain and flows dictate a more adaptive plan (though not an "artistic" plan without logic, as seen in wealthy suburbs). Lastly, do not assume that an expensive sewerage system will work because there may be insufficient 
water to make it function properly. Infrastructure should be commensurate with available resources, and burdening people with something they cannot afford is hardly a useful gift.

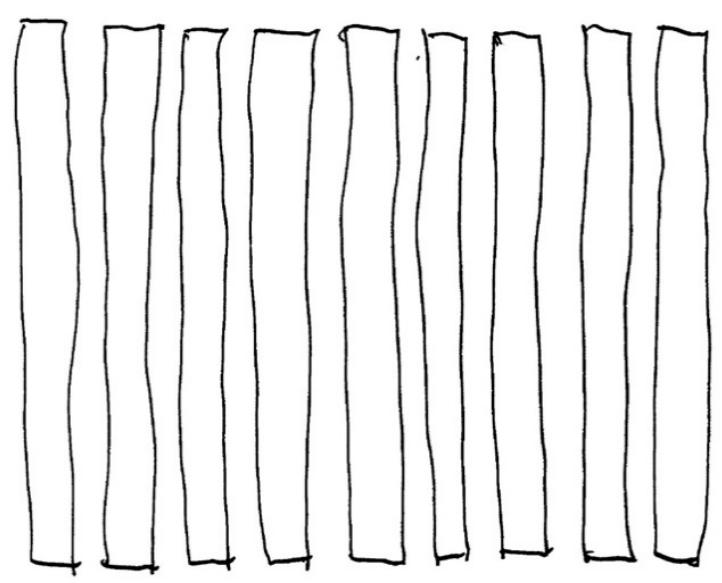

Figure 1. Unacceptable plan composed of monotonous low-rise buildings with no fractal qualities nor any useful urban space, following the industrial-modernist ideology.

Top-down planning methods now standardized by law in the industrial nations simply do not work for the majority of the world's population. The resources such projects require to implement are not there. For millennia, the model of informal, self-organized urbanism created our cities, and it is utopian to even imagine reversing this. The government is unable to provide affordable, humane housing by applying inflexible top-down schemes already biased towards industrial geometries.

\section{Fractals and the Network City}

It is not in the scope of this article to discover the distinction between vernacular settlements and slums, and why some of them gradually become middle class, whereas others remain slums. While I do not favor the term "slum" because it has negative connotations, some former informal settlements are now thriving urban neighborhoods. By focusing on the geometry, planners necessarily skip over the other contributing factors that shape what we see on the ground; most notably, the economic and social issues. Bill Hillier [9] and John Neuwirth [10] discuss how these trenchant problems-poverty, lack of resources, oppression, and social disruption-interact with the urban morphology.

The notion of fractal growth underpins the understanding of informal settlements in terms of incremental growth (Figure 2). Many researchers have worked out solutions in this vein, for example, as N. John Habraken implemented in the "Open building" project [11-13]. Habraken explicitly defines hierarchical levels of design and structure, as in fractals. Incremental building that occurs in spontaneous cities is the opposite of top-down planning that imposes predetermined forms all at once. Those are not fractal at all, being defined on only one or two scales (rather than a range of scales). Proposing a more organic and adapted methodology for housing comes up against this fundamental contradiction, which participatory urbanists try to overcome through various strategies.

Among the many deficiencies of spontaneous urban fabric is that it lacks distributed connective links [14]. In addition to terrible living conditions because of poverty and the absence of health and other essential facilities, spontaneous cities usually have no infrastructure. Minimal network access and poor connectivity result from the absence of transverse large-scale roads [15]. This last point has to do with incomplete fractality [16] because informal settlements are built by individual families, not by any higher organized entity. The small-scale plan evolves bottom-up in a highly complex, interactive process. A mathematical fractal is composed of interlocking pieces of many different sizes, whereas plainness and system fragility emphasize one scale over all the others. 


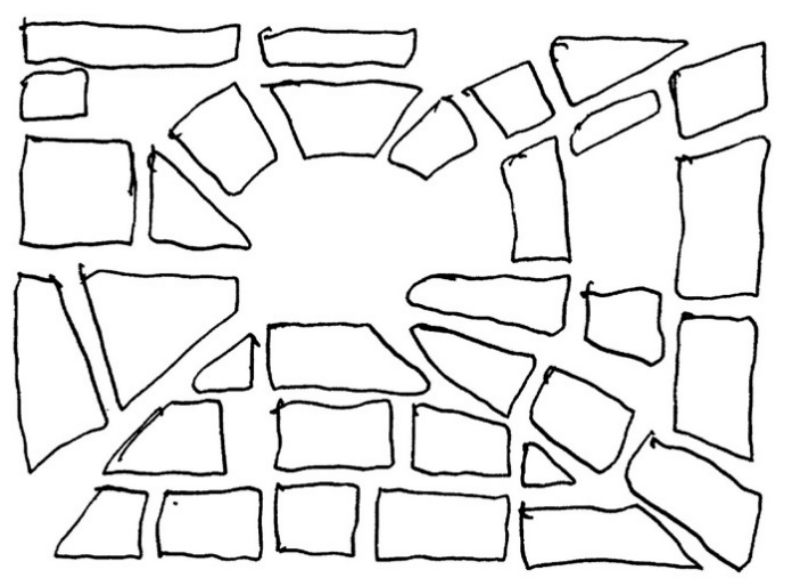

Figure 2. Roughly radial plan with a good distribution of urban spaces, where building footprints adapt to the street flows instead of sacrificing the urban space to maintain some imaginary abstract plan for the buildings' position.

A key connective difference exists between desperate slums versus healthier indigenous (but still informal) cities [17]. The former have incomplete networks on the intermediate and larger scales, and life becomes a challenge for geographically disconnected people. Despite many morphological similarities, a working informal settlement has much improved connectivity. Residents of spontaneous cities who are connected to the rest of the city can commute to work more easily. For this reason, many informal settlements grow near, or towards, local transport hubs.

Informal settlements may have good pedestrian connections but poor vehicular connections, being isolated from private transport and from any public transport network. The medieval parts of Naples and many Arab-Islamic cities illustrate this isolation. It becomes difficult, if not impossible, to insert long-scale connections after the fact [18]. This was precisely the problem that Baron Haussmann solved through his reconstruction of Paris, and Ildefons Cerdà did something similar in Barcelona. Their heavy-handed interventions (driven, in the case of Haussmann, by military considerations) destroyed dense, healthy urban fabric, but their respective results created a better-connected city overall.

\section{Organized Crime and the Threat of Cementification}

The world continues to apply the industrial-modernist design paradigm for ideological as well as profit-driven reasons. Those of us who focus on this subject have been exposed to the propaganda message of "building housing to help the poor" for so long that we fail to see its dishonesty. Massive building projects and blocks of social housing are a goldmine for those engaged in the banking, construction, financing, and real-estate industries. This observation is certainly true in efficiently run democracies. Perfectly legal profits are made from the "cementification" of the environment, and the only disadvantage lies in the product, which is often inhuman and unsustainable.

However, the actual situation is far worse on the ground. "Cementification" offers the opportunity for massive corruption [19-21]. The power game of who gets to build large projects and what typology will be applied is decided by political factors outside architecture. Cultural, moral, and religious authority is insignificant today compared to the huge money interests that drive cementification, not to mention when the financial backing of organized crime enters the picture. Land misuse often combines criminal with unsustainable practices $[22,23]$. Economic power unchecked by a concern for the users makes sure that industrial housing typologies are never questioned.

Enormous profits from rampant land speculation can make a joke out of well-intentioned regulations. A vicious cycle of land price inflation, coupled with currency devaluation, turns this process into a massive and corrupt land grab. These uncontrollable economic forces push the politically weakest out of their residences, thus continually re-setting the 
start of any solution for housing the poor. Proposals for improving the residents' health through a more enlightened urban morphology need to be backed by political support at the highest level.

Governments desperately implement slum clearance as a solution, often aided by international funding organizations [24]. This policy hardly ever helps the poor; in many cases, it only enriches well-connected businesses that develop the vacated land for profit. Watchdogs are required to monitor and block good intentions turning bad. Former residents are forcibly relocated to pre-built social housing projects on the periphery (an additional source of profit for large firms); otherwise, evicted persons are simply left to re-create their lives in another slum elsewhere. Network connectivity is cut because the new location is disconnected from places of employment, or is too expensive or distant to commute to. Even though the majority of informal settlements do not face imminent eviction, this is always a looming threat.

Clearance and redevelopment of informal settlements-whether driven by wellintentioned policy, or rapacious money-laundering schemes-destroy any existing social capital [25]. Since the replacement most often tends to be a cluster of lifeless towers with undefined public space, the end result is negative overall. The residents are subjected to trauma as this dislocation severs their economic and social networks. An informal economy that kept the people alive is disrupted, with small chance of being re-formed in the new urban geometry.

Independently of the slums' geography and major infrastructure problems, fortunes are built from the poverty of the masses [26]. Those who are economically and socially precarious are easily abused, so they need champions to protect their rights. In the worst instances, absentee land ownership guarantees exploitative rents that keep the slum residents in a state of serfdom. Deeds awarded to owner-built houses are forcibly accumulated by powerful slumlords who can enjoy a steady rental income. Even in slums, where there is no formal legal basis for land tenure, a rental operation often runs as an extortion racket.

It would seem that top-down models of planning for housing make it easy to disregard the inhabitants. The bad examples represent massive profits for the architecture-industrial complex, often linked to political corruption and organized crime. It is therefore important to discuss such schemes using the framework of urban solutions, to prevent them from becoming a profit engine for an elite group that depends on energy wastage $[27,28]$. The vast power of the energy sector works against adaptive urbanism. Well-meaning urbanists have no control in this unsustainable process; but they can try to convince political parties leading those countries to act proactively in solving the problems of poverty and urbanism.

\section{Established Forces against Informal Settlements}

The world's majority building activity has always been informal, and history documents a long and futile war by the state against the ungoverned conditions of organic urban growth $[29,30]$. It is better to channel or divert the process than to fight it blindly. Spontaneous building intuitively follows evolved biologically based rules, and is a low-energy improvised solution to pressing housing needs, despite its manifold problems. Certainly, it does not represent a good solution, and in many cases, it is only a makeshift creation in the absence of any help from above. Yet, such help typically comes with ideological baggage, which can make things worse than before.

Since the driving forces define a loosely competing but uncoordinated system working on many different levels of scale, governments cannot control the runaway urban process generating indigenous/vernacular settlements. Authorities that wish to oppose it can only apply the monolithic kind of force that they themselves exert on the city, which is why they push for centralization. It is a question of focusing top-down control [31]. Understanding those forces tries to delineate the power relationships-what agency drives what action-and not to focus only on the physical morphology [32].

People re-use available local and scrap materials for impromptu building and, so, the structures might collapse with severe weather conditions. Here is where building codes are 
sorely needed, even if sometimes impossible to enforce. An unsolvable problem is building on unsuitable land that is subject to severe climatic damage (ironically, the one error copied by the wealthy when building on "scenic" sites). Such leftover land is undesired and may not even be owned by the planned city. As an illegal settlement gets established on precarious terrain, and the already hazardous situation becomes increasingly fragile with time.

Only a fraction of indigenous or vernacular settlements are actual slums. Indigenous traditional settlements (not slums) use time-tested, energy-efficient materials and typologies. Those represent a treasure trove of re-usable solutions. Architectural culture, however, tends to dismiss all of these invaluable urban examples because: (i) their morphology contradicts approved design "images" favored by the elite (of either right or left political orientation), and (ii) the individual design freedom and variety oppose the industrial profit model favored by our top-down economic system.

Architecture depends today, to a large degree, upon deliberate design and planning by a professional caste, which perceives the organic process behind spontaneous cities as an existential threat. The industrial-modernist design paradigm decrees that people have to live in blocks of mass housing situated in-and an economic part of-large-scale industrial infrastructure frameworks [33]. Architects and planners carry, in their minds, utopian images of glass and concrete boxes originating from 1920s Germany, complete with illusory (yet powerful) ideological associations. This obsessive idea, never repudiated despite all the evidence for its human failures, shapes projects that generate an overall feeling of placelessness for users. Top-down planning for housing is a massive social experiment that ignores the often-devastating results.

The qualities of the spatial boundaries encourage pedestrian movement. Path structure, the shape of open space, and the tactile and visual attractiveness of building surfaces influence social relationships. Spontaneous social interaction can easily be interrupted by changing the socio-geometric setting. Access paths between buildings, density, physical arrangement of houses, and proximity facilitate effortless information exchange and passive contact. The paths should follow from inside to outside with no menacing portion-since psychologically uncomfortable physical distance translates into social distance. Studies show that social connectivity in public housing consisting of low-rise buildings with fairly restricted public spaces is far higher than in high-rise buildings with a lot of open space [34].

It is time for power groups to stop ignoring the radical differences in available resources and locally adaptive approaches employed by different actors in using the land. Political authority should not insist on imposing centralized solutions developed by the industrialized nations, to other less appropriate and distributed situations. Some solutions simply cannot be transferred to self-built urbanism. Infrastructure and services appropriate to industrial, wealthy regions do not work in spontaneous settlements. Innovative low-cost local solutions to sewage connections and treatment, rainwater runoff, drinking water and energy distribution are far more appropriate [35]. These alternative decentralized technologies have been successfully used throughout the developing world.

Here is where known solutions to acceptable conditions for thermal comfort and sanitary installations need to be implemented. These are known from tried-and-tested prototypes developed independently in practice in many different regions. The problem is that the architecture-industrial complex fails to validate those low-cost, low-energy solutions. Consequently, the market is left to promote its own high-profit (but often unsustainable) products, more relevant to a different economic class altogether. Regulatory agencies are easily bribed to support this racket, while money controls the marketplace through deceptive advertising.

\section{How Images Undermine Adaptation}

Architectural culture has difficulty learning from indigenous/vernacular (place-specific and owner-built) architecture [36]. This phenomenon is easily verified whenever architecture students design or build interventions in the slums of the developing world. Those 
projects-done out of a genuine concern to help - turn out to be totally out of context, and painfully disdainful of the local building culture. Through their geometry and details, those designs (illustrated in many reviews) impose an opposite worldview and tend to stick out like alien invaders. Students are falsely taught by the prevalent academic model that they know better than the people who build their own houses. Elitist arrogance is a legacy inherited from those who would design "starting from zero", ignoring millennia of evolved solutions [37].

Distinguished Asian architects such as Charles Correa and Balkrishna Doshi exemplify how modernist images weaken alternative proposals for the spontaneous city. Several generations of architects believed the declarations of early modernism in the absolute correctness of its typologies of sleek industrial images because those contrasted with traditional form languages. Those promises turned out to be illusory and, yet, the images stuck in the collective unconscious. Energy invested in applying the modernist "look" to low-cost social housing is diverted from genuinely adaptive design solutions. Working with hair-thin economic margins, any effort spent on building "image" compromises other essential components of the project.

Adaptive processes are essential to create genuinely functional and useful human environments. Because they respect human scale and movement, owner-built houses look unmistakably old-fashioned, organic, and vernacular. This is a consequence of human biology, a consequence of organic design and growth following the individual builder's emotional feedback for optimal shape and surface. Ornamentation is a necessary response to human neurological needs, and the personalization of the built environment through ornament and shaping is an established practice [25]. Certain geometrical invariants in adaptive architecture recur over millennia, and are eliminated by imposing a design "style".

When professional architects helping to house the poor produce a recognizably "modernist" result to deliberately contrast with the vernacular, then something valuable has been squandered. A portion of the extremely limited budget was spent to create modernist sculptural typologies that are irrelevant to the user's wellbeing. The original arguments against ornamentation - that it was an unnecessary and resource-wasting activity-apply instead to modernist stylistic impositions. However, whereas traditional ornament is needed by our biology, the modernist style conflicts with it.

\section{A Frame of Mind Receptive to Environmental Cues}

The adaptive, spontaneous nature of design when people build for their own survival and basic comfort is missing from formal building activity [38]. Design solutions found in informal cities could be beneficially applied to planned cities in at least two important ways. A looseness that allows adaptation can help to change monolithic top-down thinking. Then, paying attention to emotional feedback can reveal the overwhelming impact of environmental beauty on life and health. Design based on feedback from man-made forms in the environment, like those that generate indigenous/vernacular cities, precludes the alienating places that have become the industrial-modernist standard around the world.

To approach this new design paradigm, it helps to concentrate on the priorities of design under those special circumstances closest to basic survival. Economic pressures bring forth the design characteristics most immediately valuable for biological life-shaping spaces, structures, and surfaces to give us a visceral feeling of joy. By limiting attention to essential needs, the emotion-driven intuitive conception of surrounding forms contains valuable design lessons that most architects never learned. Some of these positive guidelines may be summarized as the following list of "eight priorities of the spontaneous city":

1. Focus is almost exclusively on the pedestrian realm and small-scale network connectivity.

2. Architecture utilizes manageable (softer) materials that can be shaped by non-industrial means. No large components of glass or steel are used, but mostly construction pieces on the human range of scales. 
3. All available means of ornamentation are employed, even if it is only a variety in surface texture or brightly colored paint.

4. Structures are built on the human scale, with buildings typically no more than four stories in height. This height limit, observed throughout historical and vernacular architectures, corresponds to Christopher Alexander's Pattern 21, Four-Story Limit [39].

5. Optimized low-tech and passive energy use is achieved by means of indigenous construction methods, insulation, and solar and wind orientation.

6. Energy is scarce or non-existent. Every low-cost and low-tech production means utilizes minimal amounts of generated energy.

7. Available space is scarce and, hence, it accommodates multiple uses. It is maximally used and therefore at a premium; a large open space is a luxury.

8. Car access is included where possible, but fast traffic flow is a very low priority for shaping a sustainable urban realm.

The above list, if presented as a documentation of discovered practices embedded in the morphology of spontaneous cities, could be easily dismissed as irrelevant by the entrenched power groups of the architecture-industrial complex. However, I am proposing it here as a set of guidelines to replace that system altogether. This insistence on the value of adaptive design makes it into an existential threat to the present-day global power structure. It is my intention to challenge the status quo so as to solve intractable problems threatening urban settlements worldwide.

In the process of advancing zero-energy buildings through new legislation, the above points become paramount in suggesting a framework for housing in general. These priorities apply directly to a new conception of cities, regardless of the residents' income level. The focus on pedestrian space, short-distance connectivity, sustainability through passive energy use, turning away from gigantism and skyscrapers towards more traditional dense but low-rise urban fabric, and especially the creation of a joyful environment through detail, ornament, and biophilic elements, which leads to a healthier environment free of old prejudices.

One key fact that is insufficiently emphasized, and which often escapes decisionmakers, is that spontaneous cities satisfying the above eight points maintain very high densities [40]. This achievement-fighting as it does against the multiple forces that can degrade quality of life-is remarkable. Furthermore, it belies the false justification given for high-rise industrial housing: supposedly to increase density and to generate a more "efficient" city. That statement is blatantly incorrect, yet it misleads local governments to try and replace high-density (low- to medium-rise) informal settlements with high-rise blocks. Slum clearance and redevelopment usually results in lower-density housing.

The people worst off struggle just to stay alive in spontaneous settlements. Irrelevant design criteria vanish while grasping for any components that could add physical and psychological comfort to counterbalance difficult and stressful living conditions. One step above desperate poverty, self-builders can afford to choose materials and will instinctively implement healing environments by using adaptive design. Spaces and surfaces are shaped by direct feedback from the human body interacting with the physical scale. Contextual design is conceived with locally available, low-cost materials that are cheaper to maintain long-term than imported products.

Christopher Alexander emphasizes that spontaneous building is a fundamentally interactive process and, hence, it automatically generates a psychologically healing geometry [41]. Adaptive urban form evolves from many interactive design steps and is never achieved all at once. Instead of exclusively designing in the architectural office under the influence of intellectualized design preconceptions (as is currently taught in architecture schools), there is greater human benefit when the process is derived directly on site. Indigenous/vernacular architecture is therefore our best guide to achieving this physical, visceral reality of place [42]. 


\section{What Informal Settlements Can Teach Us}

The wealthy part of the population, which creates expensive cities controlled by planning and zoning regulations, can learn from the desperately poor to conserve energy and resources. Economizing space is the opposite of vertical stacking, which wastes enormous amounts of energy and defines a hostile, inhuman public realm. Nevertheless, vertical stacking has been deceptively sold as an "economical" typology for a century because it benefits the global construction industry. Self-serving statements about energy and resource conservation in urban developments are offered as excuses for the extractive global model based on skyscrapers.

Disturbing and stark contrasts exist between a population surviving on minimal amounts of fossil energy and on meager supplies of pirated electricity, versus the glass skyscrapers of globalism brightly lit throughout the night in an ostentatious display of corporate and institutional hubris. At the same time, the world's petroleum supply is being squandered by commuters driving around suburban sprawl, and by obscenely overheated tourism consumption. Of course, media collusion with those sectors of the global economy makes sure that this wastage continues unabated [43].

Community-built dwellings turn out individually different and are uniquely adapted for their location-a variety that the top-down building industry is incapable of producing economically (Figure 3). A Faustian bargain is reached whenever the industrial-modernist approach and typologies replace the spontaneous city. In accepting them, the builder or user trade away adaptivity to the human scale for a crude and mechanical conception of the world. Proposals arising from such an industrial mind-set are hardly ever adapted to the land. The special complexity of life's processes and ecological interaction is seen to detract from the "maximally efficient" model and is therefore not allowed to influence how the land is shaped.

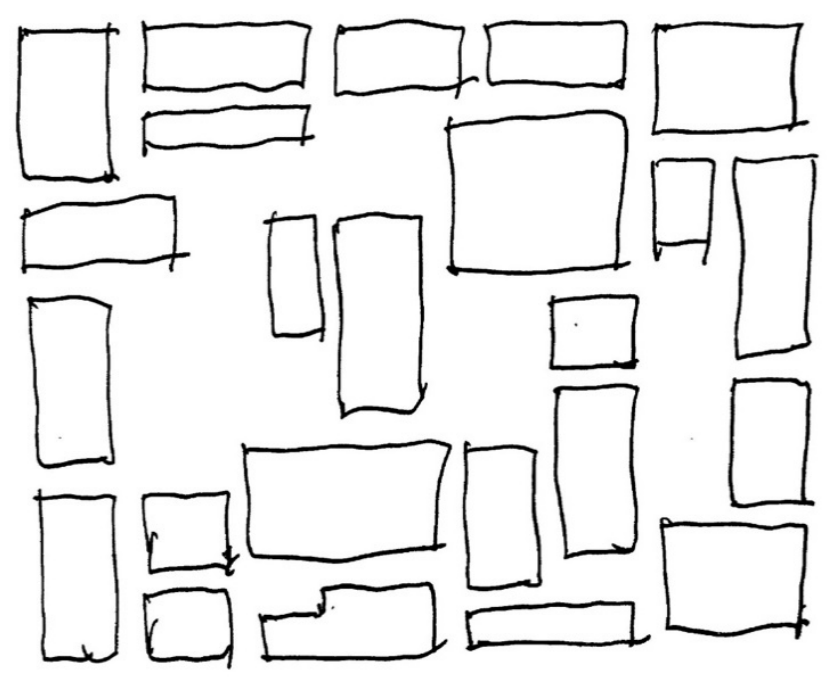

Figure 3. Acceptable plan, despite the formal rectangular grid, includes a connected distribution of urban spaces in a sequence of different sizes.

Alexander [44-47] and John Turner [48] urged a re-appraisal in how planning professionals conceive of owner-built settlements. Some flaws can be fixed inexpensively. Infrastructure and higher-scale network connectivity could be provided by the state, or by the residents helped by non-governmental organizations (NGOs) [49]. Regulatory/financial power habitually does not consider organic, collaborative solutions. Instead, a developer or the government bulldozes indigenous settlements and erects social housing blocks in their place. Or worse, the authority forcibly evicts people and then sells the land for profit. The world's poor cannot defend themselves against the financial power of a developer acting in collusion with corrupt government treating them in a feudal manner. 
Left to themselves, poor people will efficiently utilize what the wealthier segment of society has discarded, thus modifying the purely wasteful cycle of unsustainable industrial consumption. Self-builders show great ingenuity in recycling lifeless mass-produced building components, which they now employ in more adaptive and interesting ways. Unconcerned with formality, plants are used as creative additions that help to raise the biophilic qualities. The rich colors chosen whenever possible mark a decided psychological contrast with the formal city. Many cases exist where the building stock and layout are inherited from the formally planned city, as in skyscrapers (the Tower of David in Caracas) and suburban tract houses vacated by the middle class that have been recycled into lived-in slums. This type of sustainable re-use is never acknowledged officially.

Materials and energy are a primary concern for self-builders. In implementing economical re-use, the central design tenets of the planned city are irrelevant to them [50]. Success in solving the housing crisis therefore comes from encouraging community-driven development and self-help, rather than relying upon the state [51]. Formal planning grids, criteria of architectural style, and fashionable "design" are ignored in creating an informal or vernacular settlement, but human-scale ornament is essential and necessary. This re-appraisal switches the priorities of society's controlling class, which use energy and materials wastefully for an industrial-modernist tectonic "look" having nothing to do with human functions.

\section{The Failure of Developers}

Commercial developers, powerful groups or individuals, and governments predominantly decide what gets built (excluding select private residences). Out of inertia, implemented architectural and planning models could be very poor indeed, as far as adapting to the users' needs. The principal consideration is that those typologies achieved notoriety or made money previously and can be easily copied. The public, through ignorance and media manipulation, accepts minimally satisfactory typologies as judged from visceral human response $[4,38,39,41,44-47]$; therefore, that is what developers build as an effortless solution.

The business of construction is an economic engine benefitting several linked and powerful industries that define the "architecture-industrial complex". Building on speculation, not immediate needs, makes enormous profits through marketing. The industry is merely abusing the laws permitting it to do this, but it is not good urban practice. Some key negative habits (called "antipatterns") can be extracted from mainstream building activity in a listing of things to avoid and change. Those are implemented again and again, if no revisions are called for. I attempt to list working rules of a wasteful model for urban development here:

1. Find a cheap method of building that is efficient for the supporting industries of construction, finance, permitting, and regulations. Long-term upkeep and maintenance are of no concern, however.

2. Make a deal with the government authorities to allow such construction without examining the consequences on human feelings and health. Developers get away with this often enough to make the ploy worthwhile.

3. Construct as a speculative financial venture using a standardized industrial typology, then sell and get out as quickly as possible.

4. Use massive advertising to sell the units or sell the entire building wholesale to the government and let it worry about occupancy issues.

5. This business model makes social housing into an excellent profit scheme for the developer but could create a nightmare world for the eventual residents.

6. Typologies used for buildings and the urban realm religiously copy industrial modernism from the 1920s, allowing only superficial deviations and ignoring evidence that those typologies fail as human environments.

Various types of real-estate speculators implement different non-adaptive models. Many build at the city's edge on cheap agricultural land. This is assembly-line construction 
built on speculation. It is a cost-effective model because each step of the process is wellknown. The permitting process involving identical units is highly simplified and, hence, advantageous. There are no potential surprises, which deceives the developer into thinking that the product is what the market wants. In fact, by insisting on standardization, the developer restricts the market by offering only the same type of apartment or house. Competitors tend to build the same thing, manipulating supply and demand so there is really no market choice.

On already built (and possibly degraded) sites, the developer model destroys and replaces, instead of repairing existing urban fabric. In the current business plan, considerably more profit can be made from complete re-building rather than by preserving and upgrading. There is no incentive to respect anything. With developer-driven speculative (and state-supported) construction done in the cheapest possible manner, there often remains no alternative to tearing down existing structures completely before rebuilding. Perpetuating a hugely unsustainable model, this destructive practice demolishes solid building stock from the past.

Referring to the consequences of the built environment on human feelings and health opens up the discussion to recent scientific results $[52,53]$. Those were never part of conventional design and planning and, hence, do not factor in the decision-making process. The key reasons why some inadequate environments are hated include having the "wrong" geometry, spaces, paths, and details-questions that the profession never takes into consideration. This relatively recent knowledge is discussed under the topics of biophilia, design patterns, and neurodesign $[4,38,39,52,53]$.

Limited human-scale development can still occur within the top-down system. The key here is to focus on human physiology and the users' needs. Whenever a small or medium-size commercial developer decides to adopt more flexible traditional design typologies, the result is a far better product for its users. A more enlightened model is applied in "new urbanist" projects. Investors aware of market trends that value more humanly adaptive places understand that this demand translates into higher profits. Real success is observed in select new projects around the world, but those unfortunately remain marginalized from the mainstream building industry [54,55]. The fanatical bias against traditional architecture and urbanism also means that those successful models are criticized or ignored by academia and the media.

\section{Ownership Issues Prevent Upgrading}

Economic and social forces in spontaneous cities are often very adverse, and they mix with the observable urban morphology. For this reason, mechanisms due more specifically to the complexity of urban form tend to be dismissed, as sociologists focus on social problems. Mainstream urbanists are thus unlikely to want to learn something from such examples. It helps to understand these mutually dependent forces, and to try and disentangle the complex relationships that give spontaneous settlements a bad reputation.

A comprehensive study by Payne, Piaskowy, and Kuritz [56] summarizes the problems of land tenure and property rights. Prepared for a United States government aid agency that spearheads international efforts to strengthen land governance systems and tenure, the authors provide evidence for much of what this section discusses in a more anecdotal and informal manner. For example, there is false security whereby a family believes that some sort of informal tenure is achieved through access to public services and utilities, and in not being disturbed for long time periods, yet it is still subject to demolition and eviction.

The absence of land ownership in illegal settlements is a serious complication. This legal obstacle prevents a family from upgrading its house as was always done during the historical evolution of the city. It is not worth investing such effort in something that can be taken away at any moment [57]. A slum thus remains perpetually in a decayed and precarious state, with no incentive for upgrading by its residents-because they are not owners. This happens in places like Brazil and elsewhere. 
Contrast this perennial insecurity with informal settlements in countries where land deeds are awarded by the government (in Turkey, in expectation of votes!) [25]. Under favorable conditions of land ownership, informal owner-built settlements upgrade into better, permanent buildings, and we observe this process taking place today. There is a slow but striking evolution towards better-constructed and more permanent urban fabric [58]. Many countries have tenure-granting and infrastructure-upgrading programs for informal settlements. Upgrading buildings over time eventually generated historical cities as we know them. Half-measures offered by politicians in exchange for votes include communications networks and retail stores, which do not improve the settlement's physical problems.

Another set of cities was initially centrally planned as colonial or military settlements: the Hellenistic cities throughout Asia; Roman camps that evolved into European cities; and the Laws of the Indies used by the Spanish colonists to found numerous cities in Latin America. Those are still recognizable today with a rectangular Hippodamian grid at their core. Even though the morphology of these cities has survived, there is no need to wish that every spontaneous settlement fits onto a clean grid, something that has become a planning obsession based on image.

Unfortunately, manifold problems prevent a simple general solution to upgrading slums to create a better living environment. Such successes as are seen are serendipitous, and may or may not be repeatable or copied because of local conditions. The spontaneous city is not a good model for development-all that is wanted here is to isolate some of its specific morphological features. An intelligent approach to improving urban form would channel the forces of self-building and insert selected infrastructure early enough in the sequence. Along with legal validation, providing a few necessary components will help self-builders to create an informal city cheaply with a better quality of life [59].

Help and resources are desperately needed to define and maintain open spaces for children, sanitation, light, and ventilation, but not to undo what the community has already contributed to create. Acknowledging the forces driving spontaneous settlements will hopefully stop centralized government trying to replace them with products of the top-down industrial-modernist model [60]. This paper also raised the scandalous point where geometrical typologies favored by the state are disastrous from the viewpoint of maintenance and repair. Upkeep is never part of the equation where quick profits are made by building inhuman housing blocks. Those turn out to be too expensive for the poor, while their design geometry makes them unloved-hence, they are problematic to maintain.

\section{Conclusions}

Planners can learn a great deal from the spontaneous city. Design strategies found in self-built settlements could be selected and applied to make planned cities more livable. Unwritten design techniques developed through trial-and-error for primary survival were applied to build historical cities, without the need for architects or planners. Those settlements evolved into human-scaled cities with desirable emotional properties. City-building needs to be understood from the forces—good and bad-that drive those processes, and which of them pit extractive profit-making against owner-built housing.

The marketplace has failed, for the most part, to select life-enhancing architectural and urban typologies for the poor. This paper outlined some existing tools applied throughout the developing world to create emotionally nourishing environments. Energy use in spontaneous settlements has to be minimal because of the severe constraints. Materials used are inexpensive, and self-builders show great ingenuity in making do with what is available. Overall, this represents the opposite of wasteful consumption by the wealthier class using expensive imported materials.

In addition, the forms and spaces that typically arise in spontaneous building tend to be much more adaptive to human physiological and psychological needs. Design is not dictated by any type of ideology and, hence, the result provides a more emotionally 
nourishing environment coming from usually ignored details. This statement underlines the contrast between the industrial-modernist planning ideology (as described in this paper) and a more adaptive, organic approach. Adaptation happens naturally, and in spite of the often-miserable conditions in such informal cities. Then, the network and fractal conductivity of spontaneous settlements differ dramatically from those in the planned city. Each of the two types of urban morphology lacks essential connectivity on opposite scales (informal settlements lack the coherent large scale, whereas post-war formal cities lack the small scale).

No solution to planning for housing can ignore the powerful forces controlling topdown projects. Ventures are often driven by land speculation, government corruption, and organized crime and, hence, those desiring to help have to confront these problems head-on. Political will can help entrepreneurs to detach themselves from those negative forces. The inhabitants alone do not have sufficient resources to resist being manipulated by the system in a ruthless power game. They need an ally who understands the mechanics of creating humane settlements. To avoid an unsustainable disaster, it will be essential to define small-scale projects helped by a non-governmental organization.

This paper repeatedly mentions the mental block against adaptive and spontaneous design coming from architectural academia. An inherited set of images universally identified as "modern" wastes energy and resources when implemented. Because those images contradict the more organic and biologically adapted forms of spontaneous settlements, the mainstream refuses to learn from what self-builders have created throughout the ages. Rejected solutions include very intelligent typologies for thermal comfort and sanitary networks. Industrial-modernist solutions often do not apply and cannot be ported from the wealthy world to the developing world. Conditions are simply too different.

The concluding remarks are by M. N. Ashish Ganju: "Compared with the patterns preferred by official urban planners and the social elite, we believe that the urban pattern found in such spontaneous settlements is more sustainable in terms of environmental structure, a vastly reduced carbon footprint, and is more inclusive of social and economic diversity" [35].

Funding: This research received no external funding.

Acknowledgments: Many thanks to Shlomo Angel, Noah Billig, Narendra Dengle, Kim Dovey, the late Munishwar Nath Ashish Ganju, and Prasoon Kumar for their helpful comments. This essay re-uses edited parts from an earlier publication: Eight city types and their interactions, Technical Transactions-Architecture, Politechnica Krakowska, Poland 2017, 2, 5-70.

Conflicts of Interest: The author declares no conflict of interest.

\section{References}

1. Kishnani, N. Prasoon Kumar interviewed by Nirmal Kishnani. FuturArc 2020, 69, 56-63.

2. Mahabir, R.; Crooks, A.; Croitoru, A.; Agouris, P. The study of slums as social and physical constructs: Challenges and emerging research opportunities. Reg. Stud. Reg. Sci. 2016, 3, 399-419. [CrossRef]

3. Alberti, M.; McPhearson, T.; Gonzalez, A. Embracing Urban Complexity, Urban Planet; Cambridge University Press: Cambridge, UK, 2018; pp. 45-68.

4. Salingaros, N.A. Biophilia and Healing Environments; Terrapin Bright Green LLC: New York, NY, USA, 2015.

5. Angel, S. Housing Policy Matters: A Global Analysis; Oxford University Press: Oxford, UK, 2000.

6. Apte, P.M. Urban Growth Strategies: Mumbai Lessons, Rakuten Kobo; Leadstart Publishing: Mumbai, India, 2015.

7. Samidha, K. Habitat 100: A Chawl Redevelopment Project; URBZ: Mumbai, India, 2020.

8. Daminirathi. DIY Urbanism and Building with the Community, Medium.com. 8 June 2019. Available online: https://medium. com/@daminirathi/diy-urbanism-and-building-with-the-community-e909668bfe0 (accessed on 18 May 2021).

9. Hillier, B. Space is the Machine: A Configurational Theory of Architecture; Cambridge University Press: Cambridge, UK, 1996.

10. Neuwirth, R. Shadow Cities: A Billion Squatters, a New Urban World; Routledge: London, UK, 2004.

11. Habraken, N.J. Supports: An Alternative to Mass Housing; Praeger: New York, NY, USA, 1972.

12. Habraken, N.J. The Uses of Levels. Open House Int. 2002, 27, 1-17.

13. Reilly, M. An Exploration of Incremental Architecture as an Affordable Development Typology. Master's Thesis, Massachusetts Institute of Technology, Cambridge, MA, USA, 24 May 2019. 
14. Zappulla, C.; Suau, C.; Fikfak, A. The Pattern Making of Mega-Slums on Semantics in Slum Urban Cultures. J. Archit. Urban. 2014, 38, 247-264. [CrossRef]

15. Dovey, K.; van Oostrum, M.; Chatterjee, I.; Shafique, T. Towards a morphogenesis of informal settlements. Habitat Int. 2020, 104, 10224. [CrossRef]

16. Batty, M.; Longley, P. Fractal Cities; Academic Press: London, UK, 1994.

17. Dovey, K.; Shafique, T.; van Oostrum, M.; Chatterjee, I. Informal Settlement is Not a Euphemism for Slum. Int. Dev. Plan. Rev. 2020, 1-12. [CrossRef]

18. Angel, S. Urban Forms and Future Cities: A Commentary. Urban Plan. 2017, 2, 1-5. [CrossRef]

19. Weinstein, L. Mumbai's Development Mafias: Globalization, Organized Crime and Land Development. Int. J. Urban Reg. Res. 2008. [CrossRef]

20. Zhu, J. The Shadow of the Skyscrapers: Real Estate Corruption in China. J. Contemp. China 2012, 21, 243-260. [CrossRef]

21. Crosbie, M.; Fisher, T. The Ethics of Architecture and Other Contradictions, Common Edge 2019. 12 June 2019. Available online: https: / / commonedge.org/the-ethics-of-architecture-and-other-contradictions/ (accessed on 18 May 2021).

22. Chiodelli, F. The Dark Side of Urban Informality in the Global North: Housing Illegality and Organized Crime in Northern Italy. Int. J. Urban Reg. Res. 2019. [CrossRef]

23. Gallas, D. Brazil's Odebrecht Corruption Scandal Explained, BBC News. 17 April 2019. Available online: https://www.bbc.com/ news/business-39194395 (accessed on 18 May 2021).

24. Perkins, J. Confessions of an Economic Hit Man; Plume/Penguin Books: New York, NY, USA, 2005.

25. Billig, N. Istanbul: Informal Settlements and Generative Urbanism; Routledge: London, UK, 2019.

26. Davis, M. Planet of Slums; Verso Books: New York, NY, USA, 2006.

27. Jaeger, J. BlackRock: Climate Change “Defining Factor" in Companies' Futures, Compliance Week. 14 January 2020. Available online: https:/ / www.complianceweek.com/social-responsibility/blackrock-climate-change-defining-factor-in-companiesfutures / 28295.article (accessed on 18 May 2021).

28. Nietvelt, K.; Schiavo, M.; Kramarchuk, R.; Klein, D. The Energy Transition and COVID-19: A Pivotal Moment for Climate Policies and Energy Companies, S\&P Global. 24 September 2020. Available online: https://www.spglobal.com/ratings/en/research/ articles / 200924-the-energy-transition-and-covid-19-a-pivotal-moment-for-climate-policies-and-energy-companies-11651888 (accessed on 18 May 2021).

29. Njoroge, P.; Ambole, A.; Githira, D.; Outa, G. Steering Energy Transitions through Landscape Governance: Case of Mathare Informal Settlement, Nairobi, Kenya. Land 2020, 9, 206. [CrossRef]

30. Samper, J.; Shelby, J.A.; Behary, D. The Paradox of Informal Settlements Revealed in an ATLAS of Informality: Findings from Mapping Growth in the Most Common Yet Unmapped Forms of Urbanization. Sustainability 2020, 12, 9510. [CrossRef]

31. Scott, J.C. Seeing like a State: How Certain Schemes to Improve the Human Condition Have Failed; Yale University Press: New Haven, CT, USA, 1999.

32. Salingaros, N.A. The Law of Requisite Variety and the Built Environment. J. Biourbanism 2015, 4, 47-52.

33. Millais, M. Exploding the Myths of Modern Architecture; Mijnbestseller.nl: Rotterdam, The Netherlands, 2019.

34. Talen, E.; Koschinsky, J. Compact, Walkable, Diverse Neighborhoods: Assessing Effects on Residents. Hous. Policy Debate 2014, 24, 717-750. [CrossRef]

35. Ganju, M.N.A. Urban renewal by citizens. SPANDREL. J. Sch. Plan. Archit. 2012, 4, 140-149.

36. Silva, P. Not So Much about Informality: Emergent Challenges for Urban Planning and Design Education. Sustainability 2020, 12, 8450. [CrossRef]

37. Jordy, W.H. The Intellectual Migration: The Aftermath of the Bauhaus in America: Gropius, Mies and Breuer; Harvard University Press: Cambridge, MA, USA, 2013.

38. Mehaffy, M.W.; Salingaros, N.A. Design for a Living Planet; Sustasis Press: Portland, OR, USA; Vajra Publications: Kathmandu, Nepal, 2015.

39. Alexander, C.; Ishikawa, S.; Silverstein, M.; Jacobson, M.; Fiksdahl-King, I.; Angel, S. A Pattern Language; Oxford University Press: New York, NY, USA, 1977.

40. Angel, S.; Lamson-Hall, P.; Harman, O.; Wani, S. In Defence of Density, International Growth Center. 3 July 2020. Available online: https:/ / www.theigc.org/blog/in-defence-of-density / (accessed on 18 May 2021).

41. Alexander, C. The Timeless Way of Building; Oxford University Press: New York, NY, USA, 1979.

42. Asquith, L.; Vellinga, M. Editors Vernacular Architecture in the Twenty-First Century; Taylor \& Francis: Oxford, UK, 2006.

43. Saito, O. Resource Use and Waste Generation by the Tourism Industry on the Big Island of Hawaii. J. Ind. Ecol. 2013, 17. [CrossRef]

44. Alexander, C. The Nature of Order, Book 1: The Phenomenon of Life; Center for Environmental Structure: Berkeley, CA, USA, 2001.

45. Alexander, C. The Nature of Order, Book 2: The Process of Creating Life; Center for Environmental Structure: Berkeley, CA, USA, 2002.

46. Alexander, C. The Nature of Order, Book 3: A Vision of a Living World; Center for Environmental Structure: Berkeley, CA, USA, 2005.

47. Alexander, C. The Nature of Order, Book 4: The Luminous Ground, 2004; Center for Environmental Structure: Berkeley, CA, USA, 2004.

48. Turner, J.F.C. Housing by People; Marion Boyars: London, UK, 1976.

49. Mehaffy, M.; Kryazheva, Y.; Rudd, A.; Salingaros, N.A. Pattern 14.4: Incremental Self-Build. In A New Pattern Language for Growing Regions: Places, Networks, Processes; Sustasis Press: Portland, OR, USA, 2019. 
50. Balchin, P.N.; Stewart, G. Social housing in Latin America: Opportunities for affordability in a region of housing need. J. Hous. Built Environ. 2001, 16, 333-341. [CrossRef]

51. Stewart, G.; Balchin, P.N. Community self-help and the homeless poor in Latin America. J. R. Soc. Promot. Health 2002, 122, 99-107. [CrossRef]

52. Sussman, A.; Hollander, J.B. Cognitive Architecture; Routledge: New York, NY, USA, 2015.

53. Salingaros, N.A.; Sussman, A. Biometric pilot-studies reveal the arrangement and shape of windows on a traditional façade to be implicitly "engaging", whereas contemporary façades are not. Urban Sci. 2020, 4, 26. [CrossRef]

54. Schurch, T. Urban Villages, Town Design, New Urbanism: Where Does Landscape Architecture Stand? The Field ASLA. 23 April 2020. Available online: https:/ / thefield.asla.org/2020/04/23/urban-villages-new-towns-city-design-new-urbanism/ (accessed on 18 May 2021).

55. Boys-Smith, N.; Kwolek, R.; Milner, D. Permitting Beauty, Create Streets, London, UK. February 2021. Available online: https:/ /www.createstreets.com/wp-content/uploads/2021/03/Permitting-beauty_online.pdf (accessed on 18 May 2021).

56. Payne, G.; Piaskowy, T.; Kuritz, L. Land Tenure in Urban Environments, Land Links. 23 March 2014. Available online: https:/ / land-links.org/issue-brief/land-tenure-in-urban-environments / (accessed on 18 May 2021).

57. Mehaffy, M.; Kryazheva, Y.; Rudd, A.; Salingaros, N.A. Pattern 14.1: Land Tenure. In A New Pattern Language for Growing Regions: Places, Networks, Processes; Sustasis Press: Portland, OR, USA, 2019.

58. Mehaffy, M.; Kryazheva, Y.; Rudd, A.; Salingaros, N.A. Pattern 13.1: Slum Upgrade. In A New Pattern Language for Growing Regions: Places, Networks, Processes; Sustasis Press: Portland, OR, USA, 2019.

59. Mehaffy, M.; Kryazheva, Y.; Rudd, A.; Salingaros, N.A. Pattern 14.2: Utilities First. In A New Pattern Language for Growing Regions: Places, Networks, Processes; Sustasis Press: Portland, OR, USA, 2019.

60. Salingaros, N.A.; Brain, D.; Duany, A.M.; Mehaffy, M.W.; Philibert-Petit, E. Socially-Organized Housing: A New Approach to Urban Structure, Chapters published in three languages. ArchDaily Plataforma Arquit. 2019. Available online: http:// zeta.math. utsa.edu/ \{\}yxk833/social.html (accessed on 18 May 2021). 